\title{
The Fate of Isologous, Homologous and Heterologous Ferritin Molecules in the Rat ${ }^{1}$
}

\author{
S. S. HAN, I. H. HAN AND A. G. JOHNSON \\ Laboratory of Cell Biology, Dental Research Institute and Departments \\ of Anatomy and Microbiology, The University of Michigan
}

\begin{abstract}
The fate of heterologous, isologous and homologous ferritin-I ${ }^{125}$ injected into rat footpads was compared by determination of radioactivity in sera and organs, and by radioautography and electron microscopy. The clearance of heterologous ferritin$\mathrm{I}^{125}$ from circulation was significantly faster than that of isologous or homologous ferritin- $\mathrm{I}^{125}$. This was supported by measurement of radioactivity in various organs, and by radioautography and electron microscopy of popliteal lymph nodes which revealed structural details of macrophages undergoing antigen uptake.

These observations permit the following conclusions. (1) In most reticuloendothelial cells there is some nonspecific pinocytosis of antigen which is not related to immunogenicity. (2) The induction of massive immunologically specific pinocytosis by macrophages may be due to specific antigen recognition by receptors located at the cell surface. (3) Heterologous ferritin ingested by macrophages are mostly found in vacuoles or scattered in the ground cytoplasm. However, some appear in the nucleoplasm, usually in association with loose strands of chromatin materials. (4) Ferritin molecules are conspicuously absent from mitochondria, the rough-surfaced endoplasmic reticulum and Golgi apparatus. (5) The fiber-associated reticular cells of the primary nodule and germinal centers may correspond to "dendritic reticular cells" or "dendritic macrophages," capable of long-term retention of antigens.
\end{abstract}

The question of the specific recognition of foreign substances by macrophages dates back to the early observation of the phenomenon by Metchnikoff ('08). It is recorded that Metchnikoff gave his first paper on phagocytosis at Odessa in 1883. At that time he introduced the term "phagocyte" at the suggestion of Claus of Vienna to designate the mobile cells in the floating larvae of starfish, Bipinnaria, as these cells surrounded small thorns of a tangerine tree that had been introduced into the larvae. This and related early work indicated a somewhat nonspecific recognition of foreignness by phagocytic elements of lower forms. Later studies by Metchnikoff with mammals and humans clearly have demonstrated that the specific uptake of pathogenic microbes by the phagocytic cells is essential for achieving immunity (Hirsch, '65; Cohn, '68).

In recent years, morphological and biochemical events involving the uptake of various foreign substances by macrophages and subsequent intracellular processing have been clarified to a considerable extent and a number of reviews have been written (Campbell and Garvey, '63; Shands, Jr., '69; Cohn, '68). It now is clear that the physicochemical characteristics of the materials to be phagocytized are important in the process of initial trapping which appears to be independent of cellular energetics (Schumaker, '58; Brandt, '68; Marshall et al., '59; Holter, '61; Cohn and Parks, '67; Robinovitch, '69). At the same time, there is evidence that the mucoprotein coat of the cell, glycocalyx, is different among various cell types and therefore represents an intrinsic genetic dissimilarity in terms of cellular surface differentiation (Brandt, '62; Bennett, '63; Fawcett, '66). Less clear is the question of where one can draw a line between what is nonspecific physicochemical binding and what is immunologically meaningful association of antigen with the surface plasma membrane of macrophages.

The precise molecular mechanism which triggers membrane vesiculation is largely unknown, although it has been shown that the process of endocytosis and ensuing intracellular digestion require the energygenerating system of the cell (Schumaker, '58). The nature of the intracellular hy-

1 This investigation was supported in part by grants DE-02731 and AI-01524 from the National Institutes of Health, Public Health Service. 
drolysis of phagocytized or pinocytized substances has been established since the advance of the lysosomal concept (deDuve, '59). As an organelle specialized for removal of unwanted cytoplasm (autophagic vacuole and cytosegrosome) or ingested materials (phagosome), the lysosome usually achieves complete digestion of the materials, ending up with nonfunctional residual bodies (Novikoff, '63). Much of the digested protein is apparently excreted by the cell in the form of free amino acids (Ehrenreich and Cohn, '68). This is in contrast to the presumed lysosomal action on the antigens in macrophages which are capable of sparing the antigenicity of the digested substance and later transferring the antigenic information to antibody producing cells (Fishman and Adler, '63; Hunter and Wissler, '65).

Radioautographic experiments aimed at observing the topography of antigen localization have been carried out by different investigators (Nossal et al., '64; Hanna et al., '67; Cohen et al., '66; McDevitt et al., '66; Han et al., '67; Hanna and Szakal, '68; Nossal et al., '68; Herd and Ada, '69). These studies indicated that antigens, even when injected in very small amounts, localize in germinal centers and primary lymphoid nodules, especially after a second injection. Using heterologous and isologous serum proteins, Hanna et al. ('67) came to a similar conclusion that the germinal center is the site of specific concentration of heterologous antigen. Such accumulation and retention of the antigen by germinal centers has been suggested to be due to the opsonizing effect of small amounts of antibodies coating the dendritic reticular cells or macrophages (Nossal et al., '68). It has further been suggested that the ability of heterologous IgG to localize may be due to the Fc fragment (Herd and Ada, '69). Recently, Straus ('70) demonstrated the localization of horseradish peroxidase, given as antigen, in macrophages, sinusoid-lining cells, and other reticular cells of draining lymph nodes in rabbits. Almost no antigen was seen in the cortex after a primary challenge, while the reaction product was deposited at an "intercellular web" between cortical lymphocytes and reticular cells after a second injection of the peroxidase.
In the same study a distinction was made between macrophages, lining cells of sinuses and reticular cells of medullary cords.

Other than the above description by Straus, few investigators have documented relative extents of antigen uptake by different types of reticular cells. Traditionally, the term reticular cell has been applied loosely to designate stellate connective tissue cells that are associated with argyrophilic, reticular fibers of lymphoid and hemopoietic organs (Maximow and Bloom, '48). While the functional difference between the phagocytic and non-phagocytic (primitive) varieties were recognized by early workers, the question of the cell of origin of reticular fibers has not been clarified until recently (Han, '61; Han and Baker, '62). Based on electron microscopy, a third type of reticular cells in which the cytoplasm resembled a fibroblast was characterized. This type of cell was closely associated with reticular fibers, often wrapping around the latter by its cytoplasmic processes. Because of the similarity of its cytoplasm to that of a fibroblast and close relationship to reticular fibers, the cell was called a fiber-associated reticular cell.

Microscopic studies on phagocytosis have used a wide range of optical markers ranging from carbon particles, mercurial sulfide, colloidal gold, polystyrene balls and ferritin molecules to intact cells, as these substances could be visualized at various levels of microscopic scrutiny. Ferritin molecules of horse and inbred rat origin were used in this study for the following reasons. (1) Ferritin being composed of a cluster of micelles of ferric hydroxide and ferric phosphate covered by a protein coat, has a molecular weight of 495,000 or so and is antigenic when introduced into heterologous animals. (2) Being a protein ampholyte with an isolectric point at 4.4 , ferritin is soluble at neutral $\mathrm{pH}$. (3) It does not induce phagocytosis in nonphagocytic cells (Nachmias and Marshall, Jr., '61). (4) Because of its uniform molecular size, there is a greater chance for cellular uptake that is proportional to the intrinsic capacity of cells to endocytose it. (5) The appearance of micellar clusters can be recognized unmistakenly by electron microscopy. (6) The small size of the 
molecules $(\sim 110 \AA$ in diameter $)$ permits relatively free migration of the molecules through tissue spaces (Bruns and Palade, '68).

The present study demonstrates immunologically specific recognition of heterologous ferritin by macrophages of the rat. The topographic and subcellular distribution of such ferritin molecules in various types of reticuloendothelial elements of the draining lymph node are illustrated.

\section{MATERIALS AND METHODS}

Animals. A total of 212 rats were used. Inbred Lewis rats were purchased from Microbiological Associates, Walkersville, Maryland. Sprague-Dawley rats were taken from an inbred colony being developed at the University of Michigan.

Antigen. Horse splenic ferritin was purchased from Pentex, Inc., Kankakee, Illinois and was used as heterologous antigen. Rat ferritin was extracted from the spleen and liver of the inbred Lewis strain rats with ammonium sulfate followed by crystalization with cadmium. Excess cadmium was removed by dialysis against 0.1 $M$ ethylenediaminetetraacetate followed by prolonged dialysis against $0.1 \mathrm{M}$ phosphate buffer at $\mathrm{pH}$ 7.2. Rat ferritin preparations were injected into Lewis and SpragueDawley rats for the isologous and homologous series, respectively. The antigen preparations were labeled with $\mathrm{I}^{125}$ by a direct oxidation with chloramine-T using 0.5 mc of $\mathrm{I}^{125}$ per $\mathrm{mg}$ of protein (McConahey and Dixon, '66). The protein concentration was determined spectrophotometrically.

Antigen dose. A preliminary study (experiment 1) showed that the minimal dose of horse ferritin capable of invoking a primary antibody response in Sprague-Dawley rats was $0.1 \mathrm{mg}$ per animal and that an injection of $1 \mathrm{mg}$ was needed in order to induce a consistent antibody production in all animals. Therefore, a uniform dose of $1 \mathrm{mg}$ per rat was used throughout most of the experiments.

Experimental design. Table 1 records the nature of several different experiments in the present series. It may be noted that, following the preliminary studies on dose response and organ retention of heterologous ferritin, three consecutive experiments were made dealing with the same antigen (experiments 3-5). These experiments were performed in an effort to clarify our failure to observe primary antigen localization in germinal centers, an observation which has been a point of emphasis in other studies (Hanna et al., '67). Experiment 6 was a comparative study in which all animals from heterologous, homologous and isologous groups were processed simultaneously under identical conditions.

Determination of radioactivity and antibody titer. The level of radioactivity in organs and sera was determined by use of the Packard 3320 liquid scintillation spectrometer. The corrected counts per

TABLE 1

Summary of experiments ${ }^{1}$

\begin{tabular}{|c|c|c|c|c|c|}
\hline & \multirow{2}{*}{ Experiment } & \multirow{2}{*}{ Dose } & \multicolumn{2}{|c|}{ Rats } & \multirow{2}{*}{ Nature of work } \\
\hline & & & No. & $\overline{\text { Strain }}$ & \\
\hline \multirow{3}{*}{$\begin{array}{l}1 . \\
2 .\end{array}$} & & $m g$ & & & \\
\hline & Dose response & $0.01-20.00$ & 20 & SD & Antibody titration \\
\hline & Organ retention & 1 & 12 & SD & $\begin{array}{l}\text { Radioactivity determination in various } \\
\text { organs during } 24 \text { hours }\end{array}$ \\
\hline 3. & Heterologous & 1 & 24 & SD & Radioactivity determination in sera \\
\hline 4. & Heterologous & 5 & 24 & SD & $\begin{array}{l}\text { Radioautography of liver, PLN,2 } \\
\text { spleen and kidney }\end{array}$ \\
\hline 5. & Heterologous & 10 & 24 & SD & $\begin{array}{l}\text { Electron microscopy } \\
\text { Sacrificed at } 10 \text { and } 30 \text { minutes, } 3 \text { hours and } \\
1,3,7,14,21 \text { and } 30 \text { days }\end{array}$ \\
\hline \multirow{3}{*}{6.} & Heterologous & 1 & 36 & SD & $\begin{array}{l}\text { Radioactivity determination in selected } \\
\text { organs. Antibody titration }\end{array}$ \\
\hline & Isologous & 1 & 36 & Lewis & $\begin{array}{l}\text { Radioautography of PLN } \\
\text { Electron microscopy of PLN }\end{array}$ \\
\hline & Homologous & 1 & 36 & SD & $\begin{array}{l}\text { Sacrificed at } 5,10,30 \text { and } 60 \text { minutes, } 3 \text { and } \\
24 \text { hours, and } 3,14 \text { and } 30 \text { days }\end{array}$ \\
\hline
\end{tabular}

1 In all experiments antigen preparations were injected into the foot pad.

2 PLN, Popliteal lymph node. 
minute (CPM) were converted to CPM/gm or $\mathrm{ml}$ of the sample. Characterization of antibodies in circulation was achieved by a passive hemagglutination technique using tannic acid-treated sheep red blood cells (Boyden, '51).

Preparation of tissues for radioautography. Pieces of the liver, kidney, spleen and popliteal lymph node were fixed in Bouin's solution or in $2 \%$ paraformaldehyde, and double-embedded in Parlodion and Paraplast in a routine manner. Sections $4 \mu$ in thickness were coated with Kodak NTB-3 liquid emulsion and stored in slide boxes containing packets of Drierite at $5^{\circ} \mathrm{C}$. Exposure was for varying lengths of time ranging from two weeks to three months.

Tissue preparation for electron microscopy. Small pieces of popliteal lymph nodes were fixed either in $1 \% \quad \mathrm{OsO}_{4}$ in phosphate buffer or in $2 \%$ paraformaldehyde in cacodylate buffer at $\mathrm{pH} 7.4$ followed by fixation in $\mathrm{OsO}_{4}$. The fixed tissues were embedded in a mixture of epoxy resin and polymerized by graded temperatures. Thin sections were stained with lead citrate and uranyl acetate.

\section{RESULTS}

\section{Serum clearance and organ retention of ferritin- $I^{125}$ preparations}

Comparison of retention of heterologous, homologous and isologous ferritin- $-^{125}$ preparations. The results from experiment 2 indicated that, of the spleen, mesentric lymph node, thymus, liver, lung and kidney, only the spleen and liver retained a consistently high level of radioactivity during the 24 hours following injection of ferritin- $\mathrm{I}^{125}$. Hence, comparison of heterologous, isologous and homologous preparations were studied only in these organs plus kidney (experiment 6). Although the radioactivity in sera was reduced rapidly in all animals, its reduction was most pronounced in heterologous animals which showed only $24 \%$ of the ten minute value by 24 hours after injection (table 2). After the third day, when antibodies began to appear in the circulation, radioactivity in the heterologous serum was down to a value less than $10 \%$ of that at ten minutes. This should be compared to rats receiving isologous and homologous ferritin that showed only a moderate reduction at 24 hours and thereafter.

In contrast to the sera the amount of radioactivity retained by the spleen and liver was large (table 2). During the first 24 hours both of these organs in the heterologous series reached and maintained values over $100 \%$ of those at ten minutes and, thereafter, the values decreased. Compared to this, in the livers and spleens of isologous animals, the values on day 3 were less than $10 \%$ of the values at ten minutes. Although the results from the homologous series were somewhat variable, the amount of radioactivity retained in the liver of homologous animals was intermediate between the isologous and heterologous counterparts.

Unlike radioactivity in the spleen and liver, radioactivity levels in the kidneys were similar whether they were from the heterologous, isologous or homologous rats. The generally greater amount found in

TABLE 2

Clearance of ferritin- $\mathrm{I}^{125}$ preparations from various organs ${ }^{1}$

\begin{tabular}{|c|c|c|c|c|c|c|c|c|c|c|c|c|}
\hline \multirow{2}{*}{$\underset{\text { injection }}{\text { Time after }}$} & \multicolumn{3}{|c|}{ Serum } & \multicolumn{3}{|c|}{ Spleen } & \multicolumn{3}{|c|}{ Liver } & \multicolumn{3}{|c|}{ Kidney } \\
\hline & Het. ${ }^{2}$ & Iso. ${ }^{3}$ & $\overrightarrow{\text { Homo. }}$ & Het. & Iso. & Homo. & Het. & Iso. & Homo. & Het. & Iso. & Homo. \\
\hline 10 minutes & 100 & 100 & 100 & 100 & 100 & 100 & 100 & 100 & 100 & 100 & 100 & 100 \\
\hline 30 minutes & 108 & 90 & 99 & 244 & 24 & 128 & 349 & 231 & 127 & 291 & 188 & 211 \\
\hline 3 hours & 61 & 81 & 73 & 239 & 18 & 120 & 312 & 34 & 137 & 223 & 216 & 320 \\
\hline 24 hours & 24 & 70 & 60 & 131 & 13 & 40 & 160 & 10 & 36 & 104 & 110 & 200 \\
\hline 3 days & 11 & 72 & 63 & 93 & 9 & 34 & 68 & 6 & 23 & 41 & 72 & 217 \\
\hline 7 days & 9 & 64 & 55 & 48 & 9 & 51 & 46 & 5 & 8 & 22 & 63 & 68 \\
\hline 14 days & 8 & 66 & 51 & 45 & 22 & 72 & 29 & 10 & 11 & 19 & 33 & 35 \\
\hline 21 days & 6 & 66 & 55 & 93 & 15 & 78 & 53 & 6 & 17 & 14 & 24 & 15 \\
\hline 30 days & 6 & 66 & 48 & 89 & 10 & 60 & 20 & 4 & 6 & 9 & 9 & 16 \\
\hline
\end{tabular}

1 Radioactivity remaining: corrected $\mathrm{CPM} / \mathrm{ml}$ or $\mathrm{gm}$ of tissue expressed as per cent of ten minute count.

2 Heterologous ferritin-I25.

3 Isologous ferritin-I1 15 .

4 Homologous ferritin-I25. 
isologous and homologous kidneys might reflect the highly vascular nature of the organ rather than a significant uptake by phagocytosis.

\section{Radioautographic observations of popliteal lymph nodes}

Figures 1 and 2 compare the electron microscopic appearance of ferritin molecules from the horse spleen and those from rat tissues. It may be noted that both preparations are essentially the same insofar as the ultrastructure is concerned and show a few to several dense micellar cores in the individual molecules. The radioautographic illustrations used in this section are taken from experiment 6 .

Localization in sinusoidal macrophages. Within minutes after the injection of the heterologous ferritin- $\mathrm{I}^{125}$ preparation into the foot pad, radioautographs of the popliteal lymph node indicated the localization of $\mathrm{I}^{125}$ in the subcapsular and perinodular sinuses as well as in the more distal portion of the medullary sinuses. Those medullary sinuses that are near the hilar region appeared to be empty (fig. 3). Within the first hour there was a gradual movement of $\mathrm{I}^{125}$ from the peripheral sinuses toward the hilar region and by 24 hours the sinusoidal macrophages in the deep medulla were labeled intensely (fig. 4). From that time on the amount of radioactivity remaining in the lymph node decreased gradually through day 3 (figs. 5, 10). By day 7 , only a few silver grains could be recognized at low power magnifications (fig. 6).

On the other hand, radioautographs of both isologous and homologous ferritin molecules showed no distinctly concentrated patterns. This was true even at a time when there was a maximal concentration in heterologous animals (compare figs. 4, 7). At a higher magnification one could see numerous silver grains scattered over the sinusoidal space in a random manner (fig. 8). The same tendency was observed throughout later periods. For instance, figure 9 which represents a day 3 animal receiving isologous antigen, shows a number of identifiable macrophages not containing $I^{125}$ while the $I^{125}$ is visible elsewhere in the sinus.
Localization in nodules and germinal centers. The rather discrete aggregates of $I^{125}$ throughout the sinusoidal spaces and medullary cords represent individual macrophages presumed to have taken up a large number of radioiodinated ferritin molecules. The latter were mostly absent in cortical nodules (fig. 10), but were occasionally found in clusters in the diffuse cortical tissues (fig. 11). In four separate experiments, only small amounts of heterologous ferritin were found in germinal centers (fig. 12); the germinal centers were overlaid with a limited number of randomly distributed silver grains and, moreover, these were not over the macrophages (fig, 13).

\section{Electron microscopic observation of the reticulo-endothelial elements}

Macrophages of rats receiving isologous and homologous ferritin showed only an occasional uptake of ferritin molecules. Of those cells that endocytosed them, few were concentrated ferritin molecules in their cytoplasmic vacuoles. Therefore, illustrations presented here are limited to those from rats injected with heterologous ferritin molecules.

Phagocytic reticular cells and macrophages. In essence the initial steps involved in uptake of various ferritin preparations confirmed previous observations on membrane vesiculation. In figure 14 is a profile of a macrophage which showed the usual cytoplasmic features characteristic of phagocytic cells, namely, the irregular surface membrane, and the presence of numerous small vesicles and large vacuoles which contained varying numbers of ferritin molecules. The process of endocytosis was initiated by the production of a surface invagination which was relatively small and eventually pinches off by constriction of its orifice, producing small vesicles that contained ferritin molecules (fig. 15). That these vesicles might fuse to form vacuoles of larger sizes was suggested by the apparent contiguity of small vesicles (fig. 15) and by an increase in number of large ferritin-containing vacuoles at a later time (fig. 16). Some of them became several microns in diameter.

Phagocytosis of ferritin by these cells was evident as early as ten minutes after 
injection. By 60 minutes a number of large vacuoles, presumed to be produced by coalescence of smaller ones, appeared. Such large vacuoles contained aggregates of ferritin molecules that were present in association with an amorphous cloudy substance of moderate electron density and localized along the more peripheral portions of the vacuolar space (fig. 16). At later intervals, there appeared to be a gradual condensation of many of these vacuoles, apparently due to the crowding of many ferritin molecules (figs. 14, 17, 18, 19 ). By day 3 when the blood was largely cleared of ferritin, the cytoplasm of macrophages had, in addition to the ferritincontaining vacuoles, a number of vacuoles that were devoid of ferritin granules (fig. 17). This suggested a cessation of ferritin uptake while pinocytosis continued, resulting in the production of chronologically younger vacuoles that lacked ferritin molecules. The vacuoles having an interior packed with ferritin molecules resembled phagosomes described elsewhere and contained typically large aggregates of ferritin granules along with membranous and other obscure substances (figs. 18, 19).

One other notable feature which might be of functional significance was the observation that some macrophages of heterologous animals after 24 hours had a fair number of free ferritin molecoles in their nucleoplasm (fig. 19). The intranuclear ferritin granules appeared to be attached to the stringy and loose chromatin mass (arrow, fig. 19). With the exception of the aforementioned vacuoles, no other cytoplasmic organelles including mitochondria, endoplasmic reticulum and membranes of the Golgi apparatus, contained ferritin molecules. The presence of ferritin in the nucleus was not observed in homologous and isologous rats.

Littoral cells. In general, the endothelial cells that line the surface of the lymphatic sinusoids are intermediate between macrophages and fiber-associated reticular cells in terms of morphology and their capacity to take in heterologous antigen. This was evidenced by numerous invaginations of the surface plasma membrane and the presence of many vesicles and occasional vacuoles containing a considerable number of ferritin molecules (fig. 20). At the same time, they resembled fiber-associated reticular cells in that some of their cytoplasmic processes surrounded the reticular fibers of the sinusoid (fig. 21). These characteristics support our earlier radioautographic observation which indicated that littoral cells did take up a fair amount of radioactive materials but not quite as much as the fully mature macrophages and phagocytic reticular cells (Han et al., '67).

Fiber-associated reticular cells. Previous studies had established the presence of a group of reticular cells that were closely associated with reticular fibers of the mesenteric lymph node and spleen (Han, '61; Han and Baker, '62). The perinuclear cytoplasm of such reticular cells shared certain fine structural characteristics that were common to fibroblasts, namely, a relatively abundant rough-surfaced endoplasmic reticulum, the appearance of fine intracellular fibrils along the cortical cytoplasm and the presence of long slender mitochondria often with irregularly shaped cristae (fig. 22 ). In addition, occasional dense granules similar to residual bodies were found. The nucleus of these cells was generally ovoid but the nuclear membrane showed a frequently jagged contour. A fairly well developed nucleolus, but of variable size, was found in it. The fiber-associated reticular cells had elaborate cytoplasmic processes which surrounded reticular fibers (insert, fig. 22) or insinuated between neighboring lymphoid elements as found in secondary nodules.

In the present study, the fiber-associated reticular cells did not engulf and concentrate ferritin molecules to an appreciable extent. However, in small micropinocytic vesicles along the surface plasma membrane a limited number of ferritin molecules were seen (arrows, fig. 22).

Elsewhere in the intercellular space numerous ferritin molecules were associated with a cloudy substance that was presumed to be proteins of the lymph (fig. 22). Ferritin molecules were often present within individual reticular fibers. They were usually located at the interface between the plasma membrane and the fiber or attached to the surface of collagen fibrils in varying numbers (arrows, insert, fig. 22).

The uptake of ferritin by rounded elements of the lymph node has not been 
illustrated herein, due to difficulties in quantitating the relative specificity of uptake by lymphocytes which is being studied in vitro using isolated thoracic duct lymphocytes. As of now, it could be stated that the present study has confirmed the earlier finding that small lymphocytes pinocytosed heterologous ferritin (Han and Johnson, '66) and that no visible ferritin molecules have been located in plasma cells or plasmablasts.

\section{DISCUSSION}

Despite increased interest in localization of antigen in lymphoid organs, there have been relatively few studies which compared the uptake of isologous and heterologous proteins by lymphoid organs. Hanna et al. ('67) studied the uptake and radioautographic distribution of isologous and heterologous macroglobulins by dark field microscopy. They suggested that a major topographic difference between the two preparations was the specific concentration of the label in the germinal center of mice receiving heterologous protein throughout a 20-day period. Our experiments, by taking advantage of the relatively high antigenicity of the horse ferritin- $\mathrm{I}^{125}$ in rats and its visibility in the electron microscope, allow comparison in detail of the antigen clearance from sera, the pattern of distribution, and the process of pinocytosis and intracellular processing of antigen between isologous, heterologous and homologous recipients.

The immunologic specificity of recognition by macrophages. The comparison of serum clearance of various radioiodinated ferritin preparations demonstrates that removal of heterologous ferritin occurs at a significantly greater rate than either homologous or isologous preparations during the early induction (table 2). This is also borne out by the fact that both the spleen and liver contain a much greater amount of radioactivity in rats receiving heterologous ferritin when compared to isologous and homologous recipients. The large amount of heterologous ferritin molecules concentrated by those organs that are rich in reticuloendothelial elements is in support of our radioautographic and electron microscopic observations. These observations reinforce the previous contention that foreign protein molecules are removed rapidly from the serum by active macrophages and are stored in the form of phagocytic vacuoles (Novikoff, '63; Cohen et al, '66).

In this connection, an important point is the apparent similarity between isologous and heterologous animals in the fine structure of endocytosis of ferritin by macrophages. The only notable difference between the two groups was the relatively large quantity of ferritin molecules taken up and subsequently concentrated in the heterologous recipients. This would support the concept that endocytosis per se may or may not be an immunologically meaningful phenomenon, and that in macrophages, as well as in many of the unrelated cells such as fibroblasts and nerve cells (Rosenbluth and Wissig, '64), there is a level of pinocytosis which occurs independent of cellular mechanisms pertinent to immune recognition and, therefore, should be considered an epi-immunologic phenomenon. This roughly parallels the capacity of many primitive unicellular organisms to engulf almost any "non-toxic" substances present in the immediate vicinity, and hence can be explained in terms of phylogenetic requirements for nutritive activities of primitive organisms that lack a differentiated digestive system.

This being the case, one of the questions that can be asked now is how can one delineate an immunologically meaningful uptake of antigen from what might be a residual pinocytic activity of macrophages irrelevant to their defense functions. On the basis of information at hand, the following points can be made. Assuming that the formation of phagocytic vacuoles and the subsequent concentration of engulfed materials represent consequences of the endocytic activity occurring at the cell surface, the increased clearance of heterologous ferritin by macrophages must be ascribed to a heightened pinocytosis of the antigen. This would necessarily incriminate the antigen as responsible for inducing the additional pinocytosis as it comes in contact with the plasma membrane. Furthermore, the loci on the membrane where antigen-specific endocytic activities begin should be equipped with a molecular receptor(s) capable of recognizing antigenicity. 
However, conclusive elucidation of the precise molecular mechanism of immunogenic induction of phagocytosis will have to remain speculative until a more decisive answer to the question is obtained. Future insight may be gained by in vitro approaches such as those that have been attempted by a number of workers (Cohn and Parks, '67; Ehrenreich and Cohn, '67, '68; Robinovitch, '69).

Intracellular processing of heterologous ferritin. For reasons stated previously, we have characterized three different types of mature reticuloendothelial cells in the lymph node, namely, the macrophages and phagocytic reticular cells, the sinusoidal endothelium, and the fiber-associated reticular cells. Of the three cell types, it is certain that macrophages and phagocytic reticular cells represent the major cells that are concerned with the specific uptake and subsequent intracellular digestion of foreign protein molecules. The close similarity in morphology of the ferritin-containing vacuoles of these cells and phagosomes of non-immune systems can be taken as indicative of the possibility that many of the ingested ferritin molecules were extensively hydrolyzed (Ehrenreich and Cohn, '67). Such an observation may not necessarily conflict with published claims about the important role macrophages play in the retention of antigenicity of ingested materials and subsequent antibody induction (Fishman and Adler, '63), as can be explained by considering the following points.

First, the extent of intracellular digestion of antigens has not been determined accurately in this system as in many other systems. Second, there is increasing evidence that a significant amount of antigenicity of different antigens is spared from macrophagic digestion and is imparted to other immuno-competent cells (Shands, Jr., '69). Third and finally, the induction of antibody response requires only a small amount of active antigens (Nossal et al., '68).

The entry of ferritin into the nucleoplasm of heterologous macrophages is of great interest in view of the possible implication of nucleus-mediated transfer of antigenic information. Heterologous ferri- tin has also been noted to enter the nucleus of lymphocytes (Han and Johnson, '66; Han et al., '67). Wellensiek and Coons ('64) reported the presence of heterologous ferritin in the nucleus of phagocytic reticular cells, although their observation was made in animals receiving a secondary challenge of the antigen. The theoretical significance of these observations will have to be clarified through future experimentation. However, it is noteworthy that little explanation is available regarding the molecular mechanism of lysosome induction which follows phagocytosis.

Comparison of antigen uptake by different cell types and the nature of fiberassociated reticular cells. Whereas previous electron microscopic workers have seldom compared critically different types of stromal cells with respect to their capacity to take up antigen, this study clearly demonstrates that, following the phagocytic reticular cells and macrophages, littoral cells of the sinusoids rank next in endocytosis of ferritin. This is in agreement with a recent histochemical study by Straus ('70). Along with the classical claims of activation of certain portions of the vascular endothelium under challenge (Benninghoff, ' 30 ), these observations suggest that littoral cells may be intermediate in terms of their phagocytic capability and serve as a cellular reservoir for the macrophage system.

With respect to the fiber-associated reticular cells which are least active in endocytosis, their identity and morphological characteristics have been dealt with previously (Han, '61). The teleologic significance for the evolution of this cell type is understandable when one considers the necessarily rapid modification that a lymph node, challenged by an antigen, must undergo in terms of its size and, therefore, the organization of its reticular framework during a relatively short induction period. Since there are few mature fibroblasts in the lymphoid reticulum, the fiber-associated reticular cells would fulfill the functional roles of building, maintaining and modifying the fibrous reticulum of this everadapting organ; these roles are played by fibroblasts in other fibroelastic connective tissues of the body. The broad range of 
adaptation of the reticular framework may account for the wide variation in intracellular structure which may resemble that of a robust fibroblast or a quiescent fibrocyte.

The fact that many ferritin molecules are found along the surface of the fiberassociated reticular cell, especially in areas where it is in contact with reticular fibers, suggests that the cell may be comparable to the so-called "dendritic reticular cell" which is often called a "dendritic macrophage." Our findings indicate that the cell clearly does not belong to the macrophage variety insofar as morphologic criteria are concerned. The original proponents of the term "dendritic macrophage" now regularly refer to the cell as "dendritic reticular cell" (Nossal et al., '68).

Insofar as the mechanism of antigen trapping by the cell is concerned, the glycoprotein coat along the labyrinthine cell processes and the mucopolysaccharide protein complex of the ground substance that holds individual collagen fibrils in the form of a reticular fiber, may serve as ideal traps for charged protein molecules. If this be so, then one would expect ferritin molecules to be bound in these locations. This concept becomes particularly attractive when one recognizes the fact that the flow of lymph in these regions, i.e., the interfaces between reticular fibers and the fiberassociated reticular cell, would be much slower than in sinusoidal spaces. Such a condition makes the surface of this cell anatomically well suited for trapping and holding antigens, and, hence, the antibody at a later time. Thereafter, the region would become an immunologically preferential place where a specific and increased retention of antigen becomes possible, if the latter is to be introduced again. These aspects are especially pertinent in the functional consideration of primary nodules and germinal centers where reticular fibers are much finer and more delicate (deSousa, '69), and where antigen deposits are located at an "intercellular web" (Straus, '70).

In view of the foregoing, it is tempting to suggest that the terms "fiber-associated reticular cell," dendritic reticular cell" and "dendritic macrophage" be regarded as synonymous and that the cell, by virtue of its unique anatomy, may play a dual role of maintaining the fibrous reticulum and trapping antigens.

Comments on the radioautographic results. Radioautographs of the present studies support earlier work and convincingly augment the scintillation and electron microscopic results in terms of defining the comparative topography of retained antigens at the histological level. The results show clearly that isologous and homologous preparations are not taken up in significant amount by macrophages of the draining lymph node.

It is not as easy, however, to surmise an explanation for the absence of antigen concentration in germinal centers of primary nodules. The few silver grains over germinal centers (fig. 13) appear to be rather diffuse, although they may still represent a functionally meaningful distribution. Inasmuch as sensitivity of the radioautographic technique depends on a number of important factors such as precursor concentration, exposure time, etc., we have used a wide range of exposure periods and precursors of high specific activity, as well as repeating experiments in which increasing doses of antigen were employed. Despite these efforts, we have not been able to observe concentrated silver grains in germinal centers. Kerr and Middleton ('68) and Straus ('70) have also reported their failure to localize antigen in primary nodules, using horseradish peroxidase technique.

These observations suggest that localization of certain antigens in lymphoid nodules, particularly in germinal centers, during the primary response at best might occur at a very low rate. This is not to be taken as evidence against previous claims for the function germinal centers play in antibody production (Ward et al., "59) antigen retention (Nossal et al., '68); Hanna et al., '68) and immunologic memory (Wakefield and Thorbecke, '68). The recent reports that germinal centers may be responsible for IgG production and that early histologic changes in the nodules closely parallel the rise of circulating IgG calls for continued and intensified research in this area. 


\section{LITERATURE CITED}

Bennett, H. H. 1963 Morphological aspects of extracellular polysaccharides. J. Histochem. Cytochem., 11: 2-13.

Benninghoff, A. 1930 Die Capillaren. In: Handbuch der mikroskopischen Anatomie des Menschen. Julius Springer, Berlin, pp. 18-49.

Bessis, M., and J. Breton-Gorius 1961 Ultrastructure of the proerythroblast. Nouvelle Rev. Franc. Hematol., 1: 529-533.

Boyden, S. V. 1951 The absorption of proteins on erythrocytes treated with tannic acid and subsequent hemagglutination by antiprotein sera. J. Exp. Med., 93: 107-120.

Brandt, P. W. 1958 A study of the mechanism of pinocytosis. Exp. Cell Res., 15: 300-313.

- 1962 A consideration of the extraneous coats on the plasma membrane. Circulation, 26 (Suppl.): 1075-1091.

Bruns, R. R., and G. E. Palade 1968 Studies on blood capillaries. II. Transport of ferritin molecules across the wall of muscle capillaries. J. Cell Biol., 37: 277-299.

Campbell, D. H., and J. S. Garvey 1963 Nature of retained antigen and its role in immune mechanisms. In: Advances in Immunology, 3: 261-315. F. J. Dixon, Jx. and H. G. Kunkel, eds. Academic Press, New York.

Cohen, S., P. Vassalli, B. Benacerraf and R. T. McCluskey 1966 The distribution of antigenic and nonantigenic compounds within draining lymph nodes. Lab. Invest., 15: 11431155.

Cohn, Z. A. 1968 The structure and function of monocytes and macrophages. In: Advances in Immunology, 9: 193-214. F. J. Dixon, Jr. and H. G. Kunkel, eds. Academic Press, New York.

Cohn, Z. A., and E. Parks 1967 The regulation of pinocytosis in mouse macrophages. II. Factors inducing vesicle formation. J. Exp. Med, 125: 213-232.

DeDuve, C. 1959 Lysosomes, a new group of cytoplasmic particles. In: Subcellular Particles. T. Hayashi, ed. A Symposium of the American Physiol. Soc., Ronald Press, New York, pp. 128159.

de Sousa, M. A. B. 1969 Reticulum arrangement related to the behavior of cell populations in the mouse lymph node. In: Lymphatic Tissues and Germinal Centers in Immune Response. L. Fiore-Donati and M. G. Hanna, Jr., eds. In press.

Ehrenreich, B A., and Z. A. Cohn 1967 The uptake and digestion of iodinated human serum albumin by macrophages in vitro. J. Exp. Med., 126: $941-958$.

- 1968 Fate of hemoglobulin pinocytosed by macrophages in vitro. J. Cell Biol., 38: 244248.

Fawcett, D. W. 1966 External coats of the cell membrane. In: The Cell. W. B. Saunders Co., Philadelphia, pp. 345-352.

Fishman, M., and F. L. Adler 1963 Antibody formation initiated in vitro. II. Antibody synthesis in $\mathrm{x}$-irradiated recipients of diffusion chambers containing nucleic acid derived from macrophages incubated with antigen. J. Exp. Med., 117: 595-602.
Han, S. S. 1961 The ultrastructure of the mesenteric lymph node of the rat. Am. J. Anat., 109: 183-226.

Han, S. S., and B. L. Baker 1962 The reticular connective tissue cells of the rat spleen. In: Electron Microscopy. Proceedings of 5th International Congress. Vol. II. S. S. Breese, ed. pp. WW8.

Han, S. S., and A. G. Johnson 1966 Radioautographic and electron-microscopic evidence of rapid uptake of antigen by lymphocytes. Science, 153: 176-178.

Han, S. S., I. H. Han and A. G. Johnson 1967 Quantitative studies of lymphocyte mobilization and uptake of antigen by lymphocytes during primary antibody response against protein antigens. In: Germinal Centers in Immune Responses. H. Cottier et al., eds. Springer-Verlag, New York, Inc., New York, pp. 199-207.

Hanna, M. G., Jr., T. Makinodan and W. D. Fisher 1967 Lymphatic tissue germinal center localization of $\mathrm{I}^{125}$-labelled heterologous and isologous macroglobulins. In: Germinal Centers in Immune Responses. H. Cottier et al., eds. Springer-Verlag, New York, Inc., New York, pp. 86-94.

Hanna, M. G., Jr., and A. K. Szakal 1968 Localization of $I^{125}$-labelled antigen in germinal centers of mouse spleen: Histologic and ultrastructural antoradiographic studies of the secondary immune reaction. J. Immunol, 101: 949-962.

Herd, Z. L., and G. L. Ada 1969 Distribution of $\mathrm{I}^{125}$ immunoglobulins, IgG subunits and antigen-antibody complexes in rat lymph nodes. Austr. J. Exp. Biol. Med. Sci, 47: 73-80.

Hirsch, J. G. 1965 Phagocytosis. Ann. Rev. Microbiol., 19: 339-350.

Holter, H. 1961 Pinocytosis. In: Biological Struc. ture and Function, 1: 157-168. Proceedings of 1st IUB / IUBS International Symposium, T. W. Goodwin and O. Lindberg, eds. Academic Press, New York.

Hunter, R., and R. Wissler 1965 Two patterns of splenic phagocytosis. Fed. Proc., 24: 696.

Kerr, J. F. R., and G. Middleton 1968 The uptake of injected horseradish peroxidase by lysosome-rich histiocytes. J. Path. Bact., 95: 503508.

McConahey, P. J., and F. J. Dixon 1966 A method of trace iodination of proteins for immunologic studies. International Arch. Allergy Appl. Immunol., 29: 185-189.

McDevitt, H. O., B. A. Askonas, J. H. Humphrey, I. Schechter, and M. Sela 1966 The localization of antigen in relation to specific antibodyproducing cells. I. Use of synthetic polypeptide ( $T, G$ )-A-L labelled with iodine-125. Immunology, 11: 337-351.

Marshall, J. M., V. N. Schumaker and P. W. Brandt 1959 Pinocytosis of Amoebae. Ann. New York Acad. Sci., 78: 515-523.

Maximow, A. A., and W. Bloom 1948 A Textbook of Histology. Saunders, Philadelphia, pp. 77-116.

Metchnikoff, E. 1908 On the present state of the question of immunity in infectious diseases. In: Nobel Lectures, Physiol. Med., 19011921: 281-300. 
Nachmias, V. T., and J. M. Marshall, Jr. 1961 Protein uptake by pinocytosis in amoebae Studies on ferritin and methylated ferritin. In: Biological Structure and Function, II: 605-619, Proceedings of 1st IUB/IUBS International Symposium, T. W. Goodwin and O. Lindberg, eds. Academic Press, New York.

Nossal, G. J. V., A. Abbot and J. Mitchell 1964 Antigens in immunity. IV. Cellular localization of 125-I and 131-I-labelled flagella in lymph nodes. Austr. J. Exp. Biol. Med. Sci., 42: 311330.

1968 Antigens in immunity. XIV. Electron microscopic radioautographic studies of antigen capture in the lymph node medulla. J. Exp. Med., 127: 263-276.

Nossal, G. J. V., A. Abbot, J. Mitchell and Z. Lummus 1968 Antigens in immunity. XV. Ultrastructural features of antigen capture in primary and secondary lymphoid follicles. J. Exp. Med., 127: 277-290.

Novikoff, A. B. 1963 Lysosomes in the physiology and pathology of cells: Contributions of staining methods. In: Lysosomes. A Ciba Foundation Symposium, A. V. S. de Reuck and M. P. Cameron, eds. Little, Brown and Co. Boston, pp. 36-77.

Robinovitch, M. 1969 Uptake of aldehydetreated erythrocytes by L 2 cells. Exp. Cell Res. 54: $210-216$.

Rosenbluth, J., and S. L. Wissig 1964 The dis tribution of exogenous ferritin in toad spinal ganglia and the mechanism of its uptake by neurons. J. Cell Biol., 23: 307-325.
Schumaker, V. N. 1958 Uptake of protein from solution by Amoeba proteus. Exp. Ceil Res., 15: 314-331.

Shands, J. W., Jr. 1969 The immunological role of the macrophage. In: Modern Trends in Immunology, 2: 86-118. R. Cruickshank and D. M. Weir, eds. Appleton-Century-Crofts, New York.

Straus, W. 1970 Localization of the antigen in popliteal lymph nodes of rabbits during the formation of antibodies to horseradish peroxidase. J. Histochem. Cytochem., 18: 131-142.

Wakefield, J. D., and G. J. Thorbecke 1968 Relationship of germinal centers in lymphoid tissue to immunological memory. I. Evidence for the formation of small lymphocytes upon transfer of primed splenic white pulp to syngeneic mice. J. Exp. Med., 128: 153-169.

1968 Relationship of germinal centers in lymphoid tissue to immunological memory. II. The detection of primed cells and their proliferation upon cell transfer to lethally irradiated syngeneic mice. J. Exp. Med., 128: 171187.

Ward, P. A., A. G. Johnson and M. Abell 1959 Studies on the adjuvant action of bacterial endotoxins on antibody formation. III. Histologic response of the rabbit-spleen to a single injection of a purified protein antigen. J. Exp. Med., 109: 463-474.

Wellensiek, H., and A. H. Coons 1964 Studies on antibody production. IX. The cellular localization of antigen molecules (ferritin) in the secondary response. J. Exp. Med., 119: 685-696. 


\section{PLATE 1}

EXPLANATION OF FIGURES

1-2 Electron micrographs of purified ferritin preparations from the horse and rat spleen, respectively. Many molecules show the micellar cores in both preparations (arrows). Approximately $\times 285,000$.

3-6 Low power radioautographs of the popliteal lymph node taken from rats receiving $1 \mathrm{mg}$ of heterologous ferritin- ${ }^{12.5}$, sacrificed at ten minutes (fig. 3), 24 hours (fig. 4), three days (fig. 5) and 7 days (fig. 6) after the injection. Note the changes in the pattern of topographic distribution and the number of silver grains. $\times 36$.

7 A low power radioautograph of the popliteal lymph node from a rat sacrificed at 24 hours after the injection of $1 \mathrm{mg}$ of isologous ferritin-I ${ }^{125}$ preparation. In contrast to figure 4 , which is the comparable heterologous recipient in terms of sacrifice time, there is a conspicuous lack of silver grains over this node. $\times 40$. 
S. S. Han, I. H. Han and A. G. Johnson
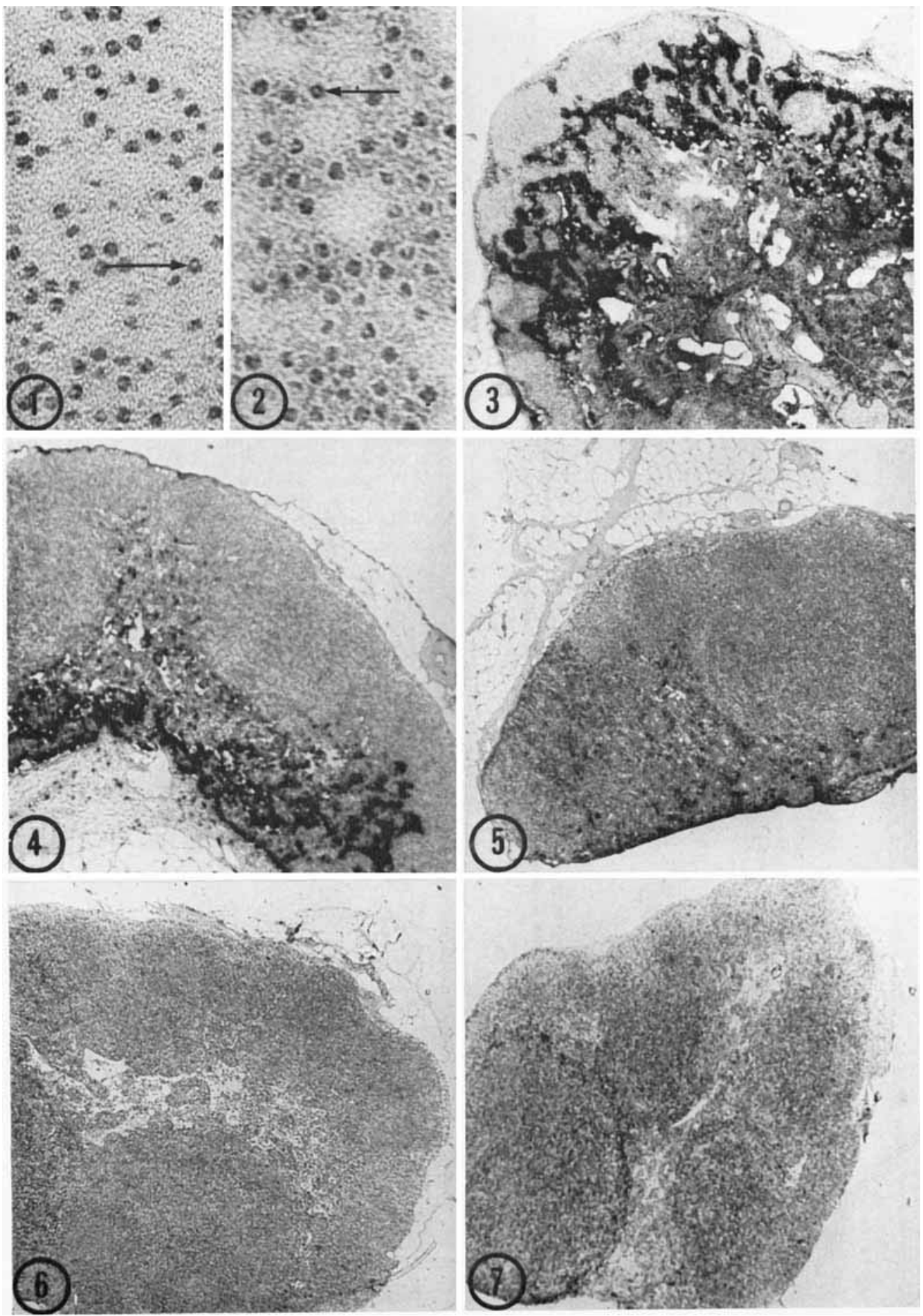
PLATE 2

EXPLANATYON OF FIGURES

8-9 Radioautographs of the popliteal lymph node from rats sacrificed at 24 hours and three days after the injection of isologous ferritin$I^{125}$ preparation, respectively. Note the presence of fairly abundant but randomly distributed grains in figure 8 . Although some grains are seen in figure 9 , few macrophages appear to concentrate the silver grains (arrows) $\times 480$.

10-13 Radioautographs of popliteal lymph nodes from rats sacrified at three or seven days after the injection of heterologous ferritin$I^{125}$. Figure 10 ( 3 days) shows numerous patches of silver grains located in the region of cortical sinuses and medullary cords (upper left). The lower right half of the photograph is a portion of a cortical nodule which is devoid of silver grains. In figure 11 ( 3 days) are present several patches of silver grains in the diffuse cortical lymphoid mass. Figure 12 ( 7 days) illustrates a germinal center. Note the presence of tingeable body macrophages and the lightly stained cells of the center (GC). Figure 13 ( 7 days) depicts a portion of the germinal center at a higher magnification and shows few concentrated silver grains, although there are a fair number of them scattered throughout the germinal center. $\times 120$ (figs. $10,11,12$ ) and $\times 480$ (fig. 13 ). 
S. S. Han, I. H. Han and A. G. Johnson

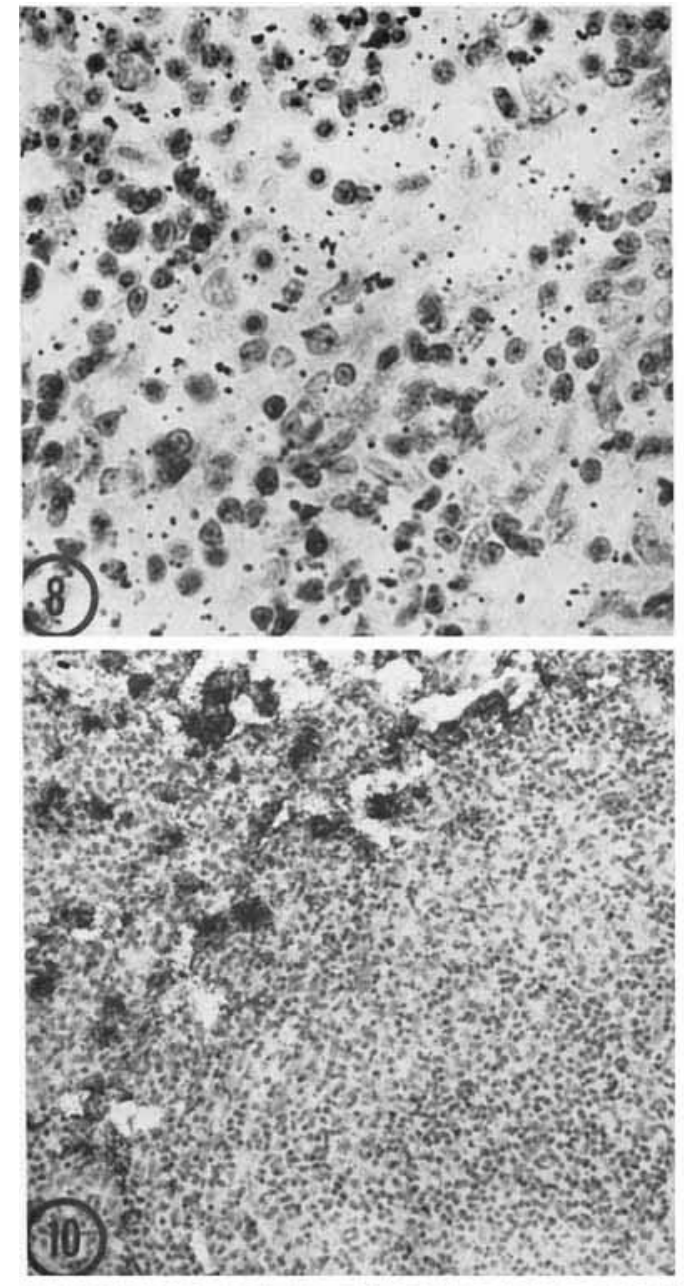



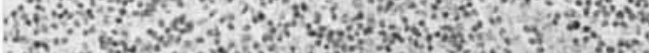

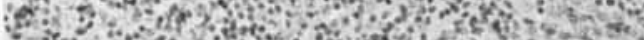



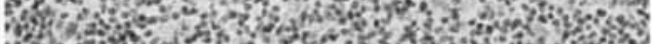



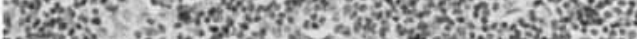

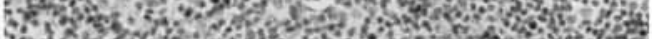
F. 4. 50 . $3 x^{2}+2$.

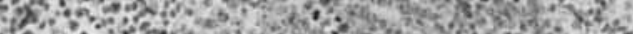

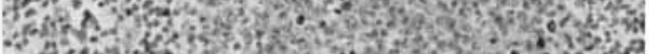





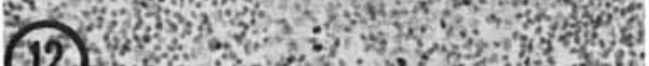
(12)
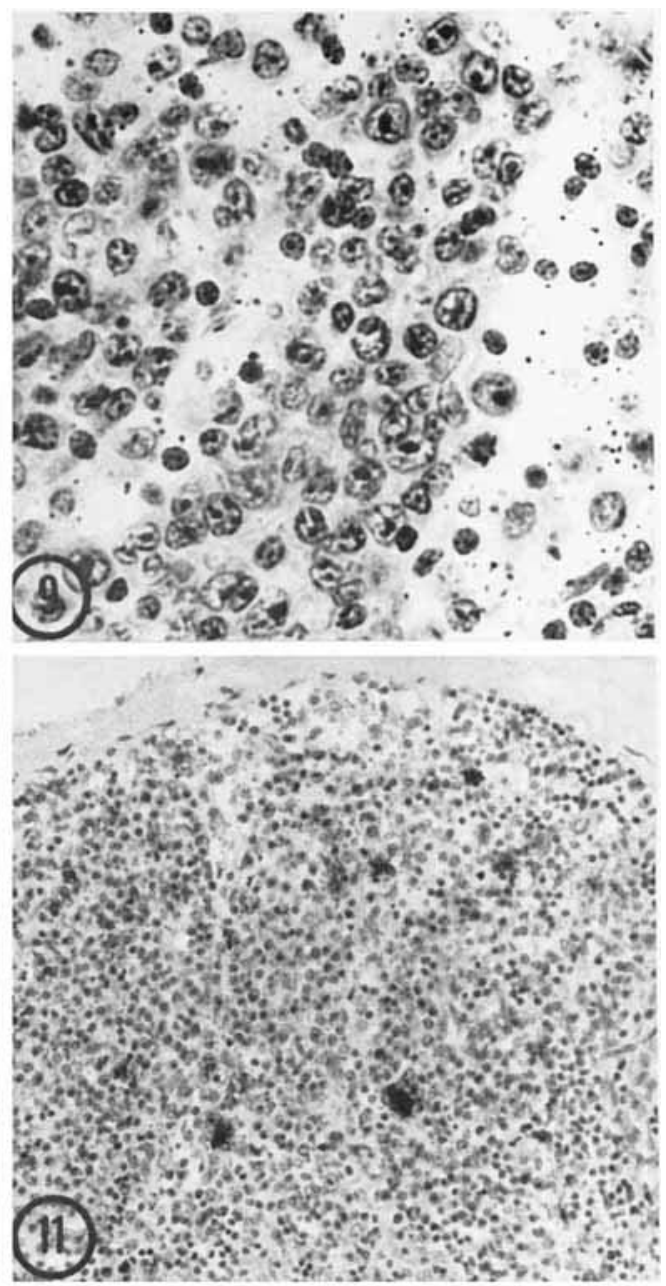

से



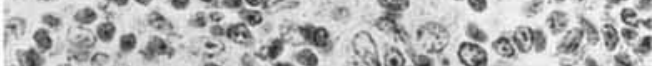

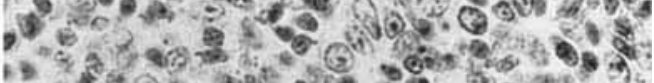

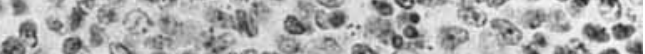

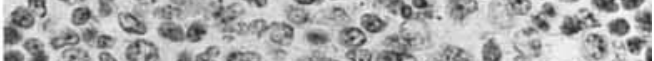

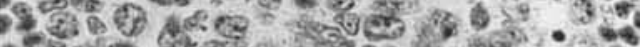

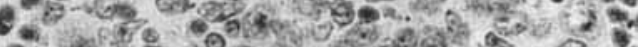

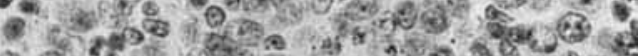

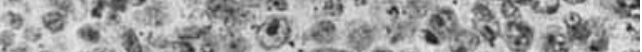

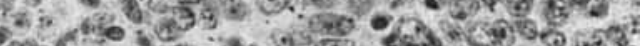

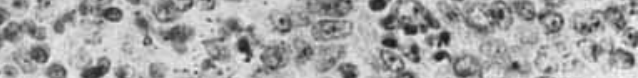

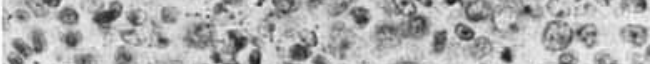

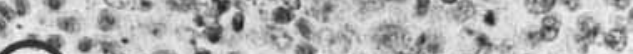

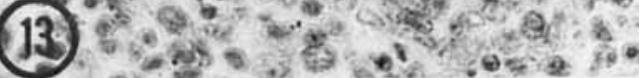




\section{PLATE 3}

EXPLANATION OF FIGURE

14 A low power electron micrograph of a macrophage from the popliteal lymph node of a rat sacrificed at 24 hours after injection of the heterologous ferritin- $\mathrm{I}^{125}$. The cell shows the usual characteristics of the macrophages in action, namely, numerous small vesicles and vacuoles( $(v)$, some of which are packed with ferritin molecules (arrows). $\times 6,400$. 


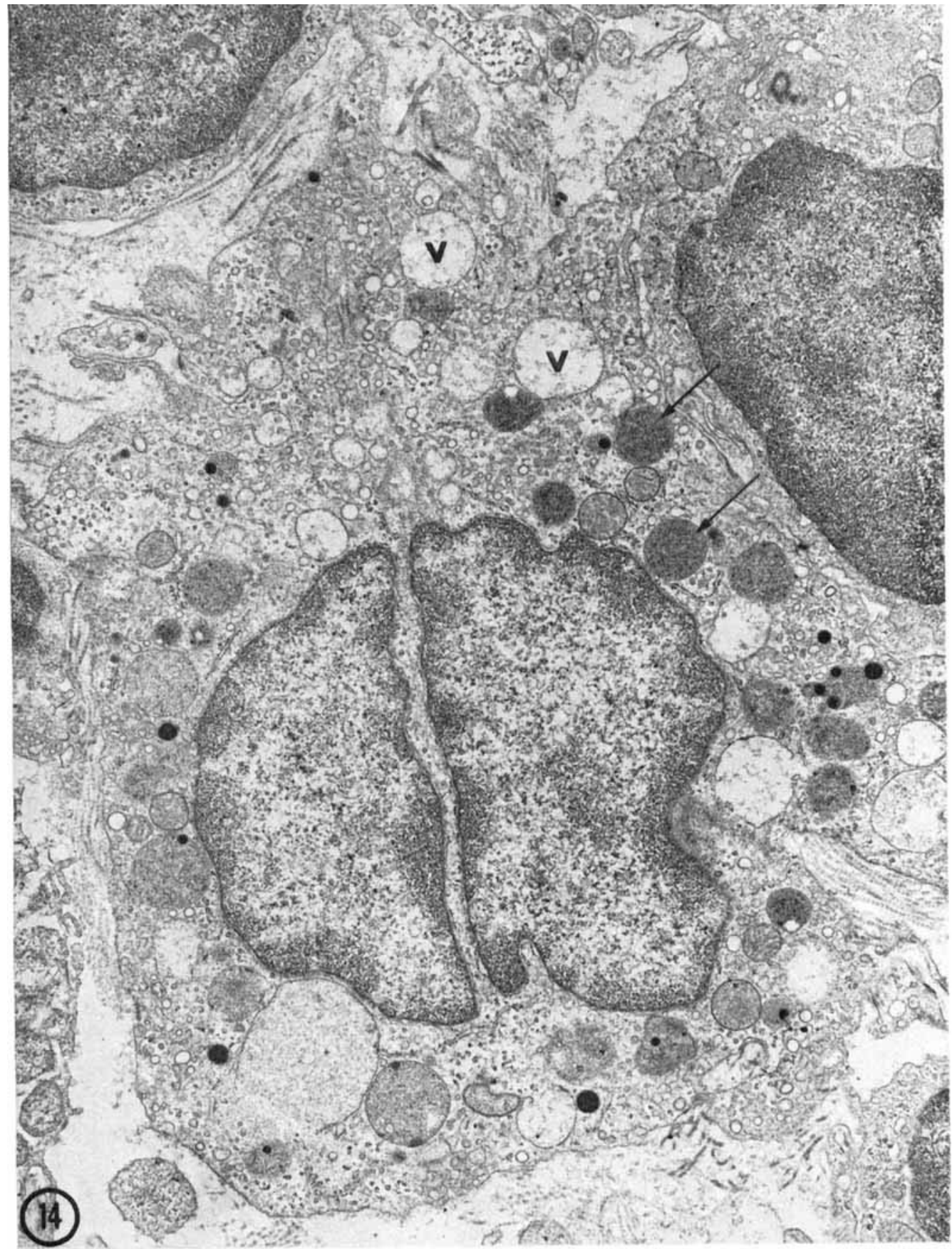




\section{PLATE 4}

EXPLANATION OF FIGURES

15 A portion of a macrophage from the popliteal lymph node of a rat sacrificed at ten minutes after injection of the heterologous ferritin$\mathrm{I}^{125}$. Note the invaginations(1) of the surface plasma membrane which appear to pinch off to form small vesicles(2) containing ferritin; they may coalesce to form a larger vacuole(3). E; extracellular space. $\times 48,000$.

16 A portion of a unacrophage of the popliteal lymph node of a rat sacrificed at 60 minutes after injection of the heterologous ferritin$\mathrm{I}^{125}$. Note the two large vacuoles containing a large number of ferritin molecules aggregating near their periphery. It appears that most of the ferritin molecules are present in association with the cloudy electron-dense matrix of the region(arrows). $\times 48,000$. 
S. S. Han, I. H. Han and A. G. Johnson

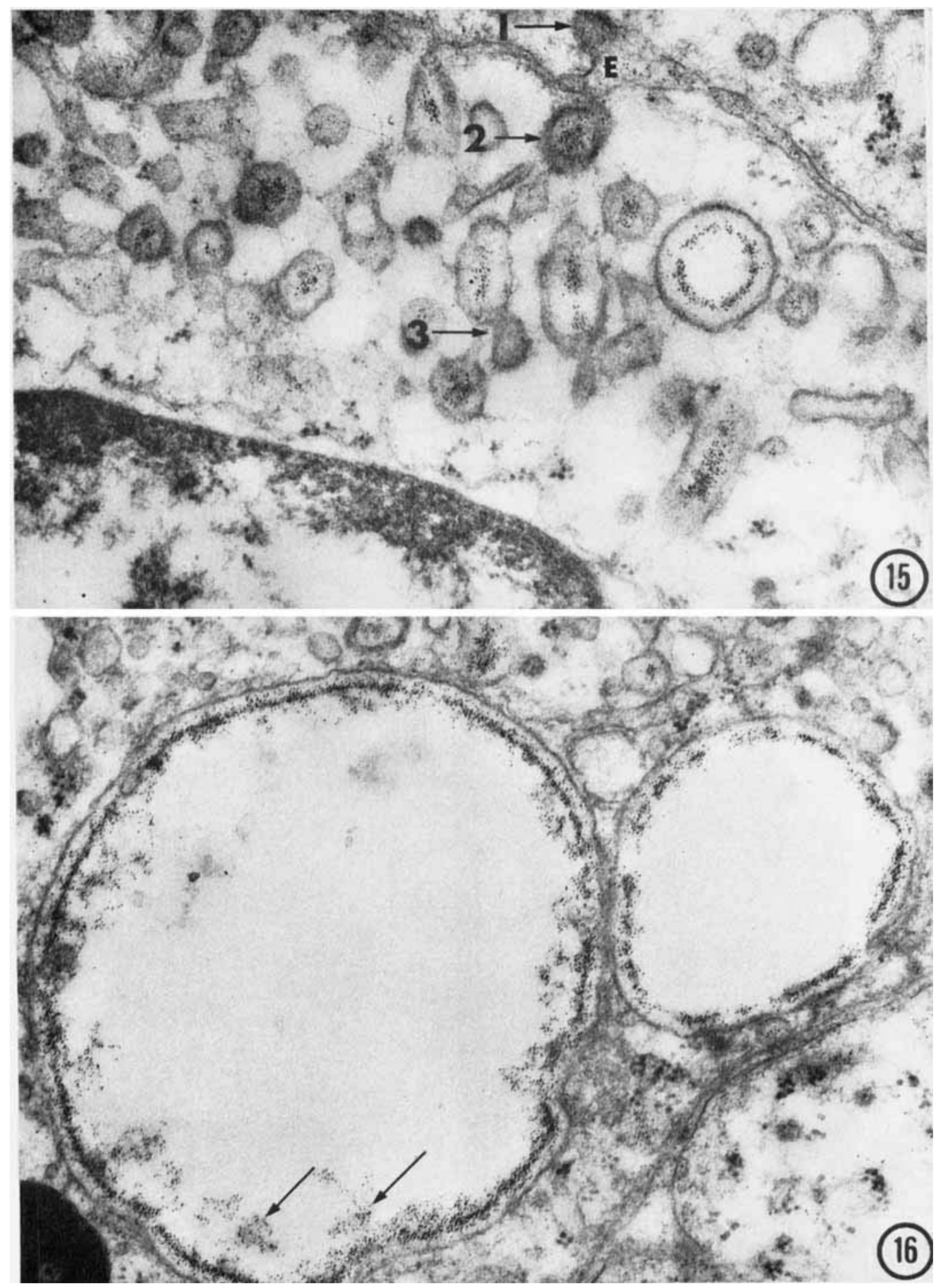


PLATE 5

\section{EXPLANATION OF FIGURES}

17 A portion of a macrophage from the popliteal lymph node of a rat sacrificed at three days after the injection of heterologous ferritin-I ${ }^{125}$. By this time many macrophages show cytoplasmic vacuoles some of which are filled with ferritin molecules(long arrows) whereas others are devoid of visible molecules(short arrows). Most of the empty ones are of small size. Since many of the blood-borne ferritin molecules have been cleared up by this time, the picture suggests that the clear and small vacuoles represent more recently formed vacuoles rather than ferritin-containing ones. $\times 17,600$.

18 A portion of a large aggregate of ferritin and unidentified materials present in a macrophage of the popliteal lymph node of a rat sacrificed at three days after injection of heterologous ferritin- ${ }^{125}$. Although this is one of the unusually large masses, there are many such aggregates that may reach 2 to $3 \mu$ in diameter. $\times 18,200$. 

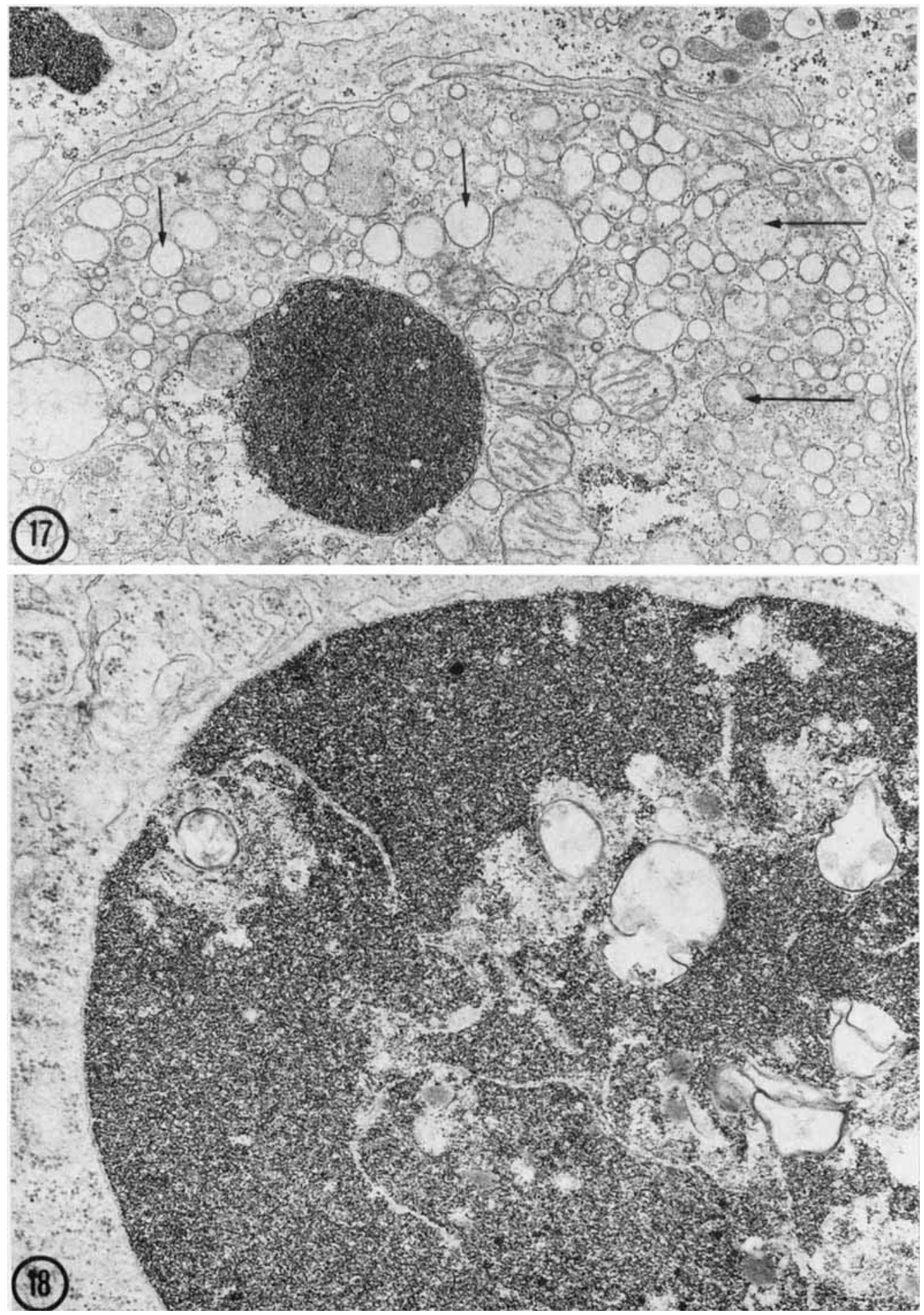
PLATE 6

EXPLANATION OF FIGURE

19 A portion of a macrophage from the popliteal lymph node of a rat sacrificed at 24 hours after the injection of heterologous ferritin- ${ }^{125}$. In addition to usual aggregates and isolated ferritin molecules that are found in the ground cytoplasm, the nucleoplasm also contains a fair number of ferritin granules(circles). Most of them appear to be attached to loose strands of chromatin materials(arrow). Note also the absence of ferritin granules in the perinuclear cisternae, roughsurfaced endoplasmic reticulum and mitochondria, $\times 42,600$. 


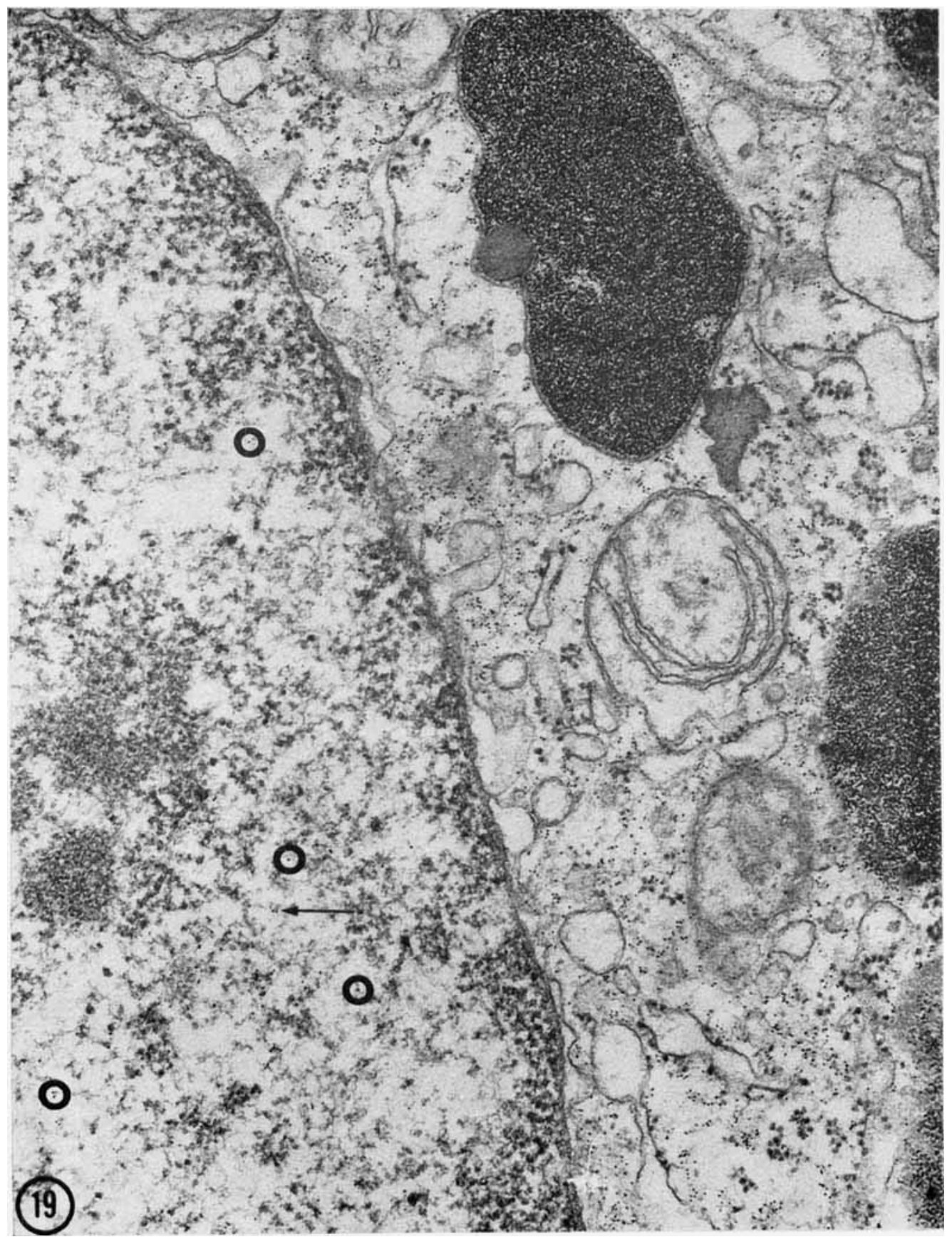


PLATE 7

EXPLANATION OF FIGURES

20-21 Portions of endothelial cells that line the sinusoidal wall of the popliteal lymph node of a rat sacrificed at 60 minutes after the injection of heterologous ferritin- $\mathrm{I}^{125}$. Note the active pinocytosis of ferritin molecules by the surface membrane of the cell in figure 20 (axrows). Figure 21 shows two reticular fibers(f) that are completely surrounded by the cytoplasm of an endothelial cell. $\times 8,600$. 

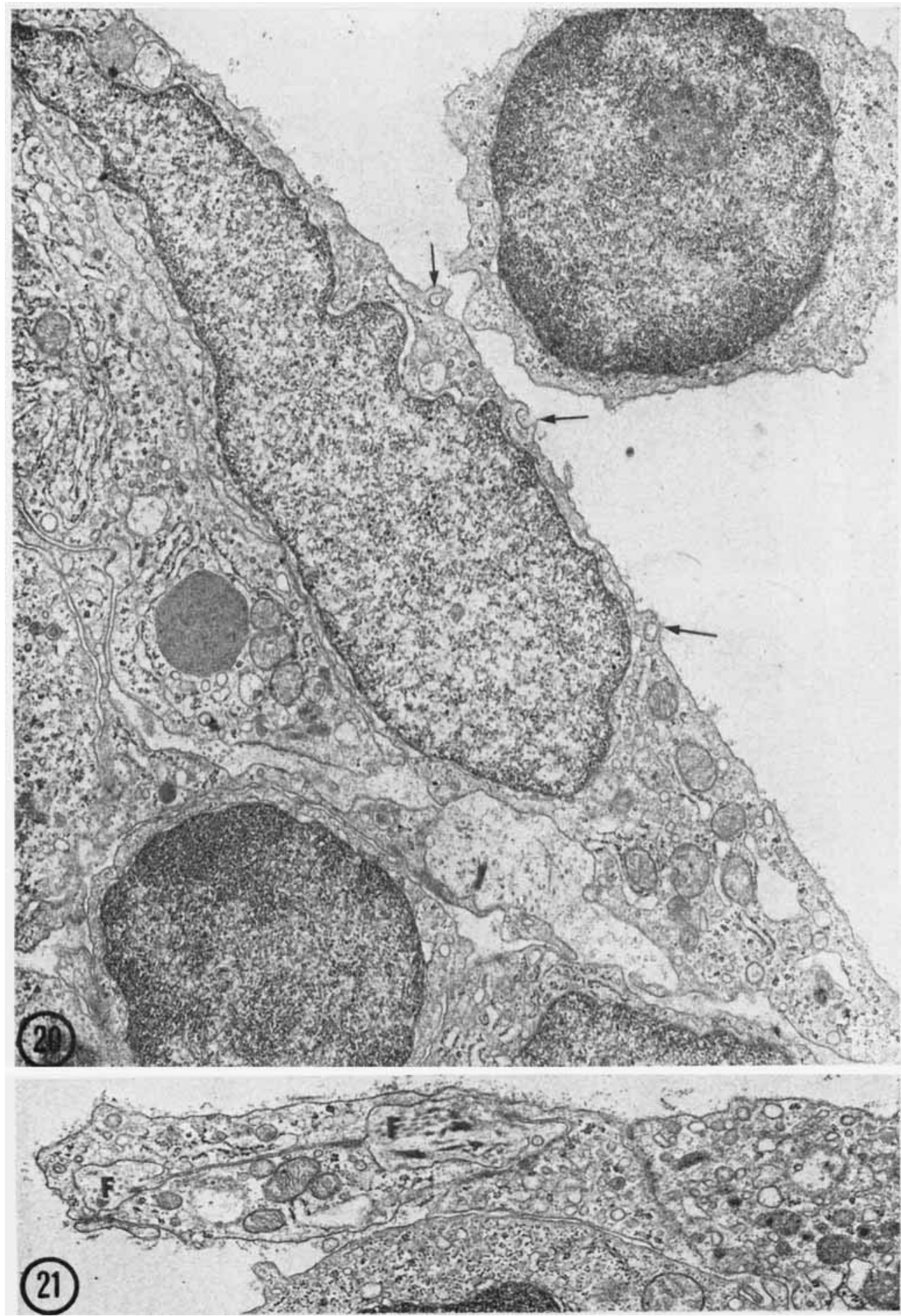
PLATE 8

EXPLANATION OF FIGURE

22 A fiber-associated reticular cell from the popliteal lymph node of a rat sacrificed at three days after injection of the heterologous fer ritin- $\mathrm{I}^{\mathbf{2} 25}$ preparation. It has a cytoplasm containing a fair amount of rough-surfaced endoplasmic reticulum, elongate mitochondria, and a nucleus with jagged contour and fair sized nucleolus. This cell is associated closely with reticular fibers $(F)$ and takes up a small number of ferritin molecules (arrows). Often the fibers are surrounded completely by the cytoplasm of the fiber-associated reticular cell as indicated in the insert. Note also that the insert shows small ferritin molecules in association with the cell surface, as well as with the surface of individual collagen fibrils that make up the reticular fiber (arrows). $\times 10,200$. Insert $\times 28,000$. 


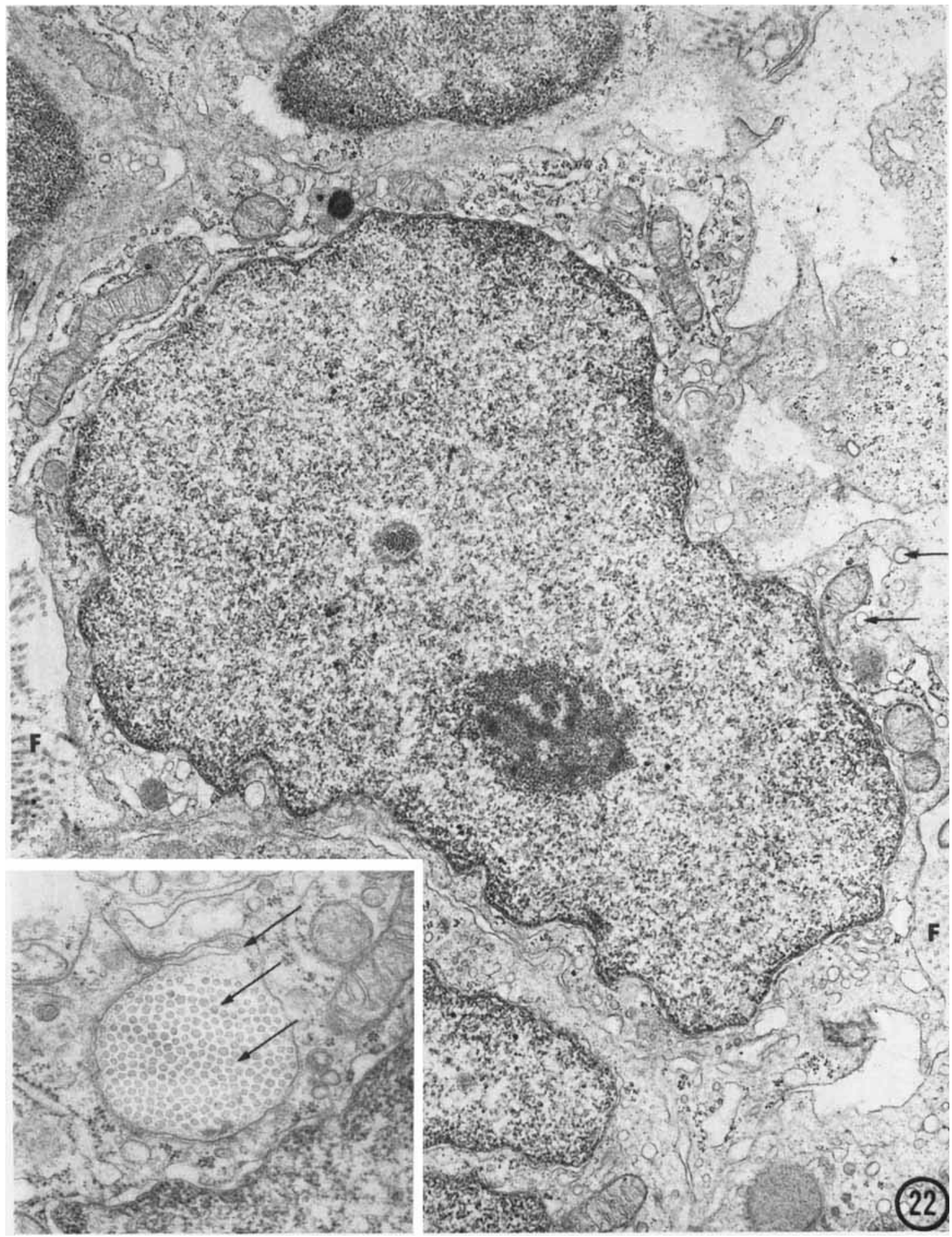

